\title{
Crustal phases across the Iberian Peninsula Region
}

\author{
Goxzalo Payo $\left(^{*}\right)$ \\ Ricevuto l'8 Agosto 1964
}

SUMmary. - A large collection of seismograms from near earthquakes recorded at Toledo Observatory have heen revised in order to get the caracteristies of the crustal phases for the Iherian Peninsula Region. After a careful determination of the parameters of the earthquakes, hy using all the Spanish Seismological Stations. 39 of them have been selected and grouped in three caracteristic groups corresponding to the regions named Algeria, Alhoran Sea and rest of the Peninsula, which have been studied comparatively.

With the arrivals of the different phases to Toledo Observatory and hy means of the least squares method the next travel time equations for the crustal wave propagation through the Iherian Peninsula have heen computed:

$$
\begin{aligned}
& P n(n=25) t=A /(7.58 \pm 0,21)-1.92 \\
& P^{*}(n=15) t=\Delta /(7.2 \pm \pm 0,26)+7.60 \\
& P g(n=19) t=d /(5.89 \pm 0,20)+1.94 \\
& S n(n=18) t=A /(4.35 \pm 0,09) \div 5.08 \\
& S^{*}(n=16) t=A /(3.66 \pm 0,09)-2.30 \\
& S g(n=20) t=d /(3.29 \pm 0,11)-2.92
\end{aligned}
$$

The Spanish Stations loeated at the Mediterranean Coast have been used to determine the following equations for the meditteranean paths hetween Algeria and the Peninsula:

$$
\begin{aligned}
& t=\Delta /(7.96 \pm 0.26)+4.95(n=24) \quad \Delta>200 \\
& t=\Delta /(5.71 \pm 0.28)-3.19(n=16) A<200 \\
& t=\Delta /(4.33 \pm 0.15)+3.12(n=22) A>200 \\
& t=\Delta /(3.15 \pm 0.18)-8.50(n=14) \quad A<200
\end{aligned}
$$

Making use of all these crustal velocities ohtained we have determined and approximate value for the crustal thickness for the Peninsula continental area $(H$ ahout $31 \mathrm{~km}$ ) as well as for this arm of the Mediterranean Sea

(*) Observatorio Central Geofisieo (Instituto Geografico y Catastral). Toledo, Spain. 
here considered ( $I$ about $25 \mathrm{~km}$ ). These values are only approximated and they will be checked in a second paper about dispersion of the surface waves through this same area.

Relative energies among the different phases have been also studied, being the distance the predominant factor in the correlation. It appears clearly that, for each earthquake given, more energy passes to the shear waves than to their corresponding longitudinal waves. Also $P g$ seems to be relatively nore attenuated with the distance than the corresponding $P n$ and $s g$ for each carthquake given. $P g$ and $S g$ of the Mediterranean Sea between Algeria and Spain are recorded very weakly or not recorded at all. However earthquakes from Alboran region grive, at Toledo, clear records of these two phases.

Riassunto. - Sono stati controllati un gran numero di sismogrammi relativi a terremoti vicini registrati dall'Osservatorio di Toledo, allo scopo di dare le caratteristiche delle fasi interessanti la crosta iella Penisola Iberica. Dopo una accurata determinazione dei parametri dei terremoti, servendoci di tutte le stazioni sismiche sparnole, sono stati scelti 39 di essi e riuniti in tre gruppi caratteristici, concernenti l'Algeria, il Mar di Alboran ed il resto della Penisola, studiati e poi messi a confronto.

Per mezzo dei tempi di arrivo delle diverse fasi all'Osservatorio di Toledo, sono state calcolate, con il metodo dei minimi quadrati, le dromocrone relative alla propagazione delle onde sulla crosta attriverso la Penisola Iberica.

$$
\begin{aligned}
& P n(n=25) t=\Delta /(7.58 \pm 0.21)+1.92 \\
& P^{*}(n=15) t=\Delta /(7.24 \pm 0.26)+7.60 \\
& P g(n=19) t=\Delta /(5.89 \pm 0.20)+1.94 \\
& S^{\prime}(n=18) t=\Delta /(4.35 \pm 0.09)+5.08 \\
& S^{*}(n=16) t=\Delta /(3.66 \pm 0.09)-2.30 \\
& S g(n=20) t=\Delta /(3.29 \pm 0.11)-2.92
\end{aligned}
$$

Per determinare le equazioni relative ai tragitti mediterranei, compresi fra l'Algeria e la Spagna ci siamo serviti delle stazioni dislocate lungo la costa Mediterranea.

$$
\begin{aligned}
& t=\Delta /(7.96 \pm 0.26)+4.95(n=24) \Delta>200 \\
& t=\Delta /(5.71 \pm 0.28)-3.19(n=16) \Delta<200 \\
& t=\Delta /(4.33 \pm 0.15)+3.12(n=22) \Delta>200 \\
& t=\Delta /(3.15 \pm 0.18)-8.50(n=14) \Delta<200
\end{aligned}
$$

Facendo uso delle velocita ottenute per la crosta, abbiamo determinato sia i valori approssimati dello spessore della crosta dell'area continentale della Penisola $(I I \cong 31 \mathrm{~km}$ ), sia quelli concernenti il braceio del Mar Mediterraneo da noi preso in esame $(I I \cong 25 \mathrm{~km})$. Questi valori sono solo approssimativi e saranno migliorati in una seconda nota sulla dispersione delle onde superficiali attraverso la stessa zona.

Abbiamo inoltre studiato l'energia relativa sviluppata nelle diverse asi, provando che la distanza e un fattore determinante. Appare chiaro che, 
per ogni terremoto, si trasmette maggiore quantita di energia nelle onde trasversali che nelle corrispondenti onde longitudinali.

Sembra inoltre che le onde $P g$ si attenuino, con la distanza, maggiormente delle $P n$ ed $S g$ corrispondenti (sempre per ciascun terremoto): mentre le $P g$ ed $s g$ - attraverso il Mar Mediterraneo compreso fra l'Algeria e la Spagna - sono registrate o molto debolmente o per niente. Al contrario. nei terremoti provenienti dalla zona compresa fra il Mar di Alboran e Toledo, queste due fasi sono chiaramente registrate nei sismogrammi.

Resumen. - Una gran coleccion de sismogramas de terremotos proximos registrados en el Observatorio de Toledo ha sido revisada para obtener las caracteristicas de las fases corticales a traves de la region de la Peninsula Iberica. Tras ma cuidadosa determinacion de los parametros de los sismos. usando las estaocines españolas, 39 de ellos han sido seleccionados y agrupados en tres grupos caracteristicos correspondientes a las regiones denominadas, Argelia, Mar de Alboran y el resto de la peninsula. Dichos grupos de sismos han sido estudiados comparativamente.

Con los tiempos de llegada de las diferentes fases al Observatorio de Toledo, se han determinado por medio del metodo de mínimos cuadrados, las siguientes ecuaciones de propagacion para las fases corticales a traves de la Peninsula Iberica.

$$
\begin{aligned}
& P n(n=25) t=d /(7.58 \pm 0.21)+1.92 \\
& P^{*}(n=15) t=A /(7.24 \pm 0.26)+7.60 \\
& P g(n=19) t=A /(5.89 \pm 0.20)+1.94 \\
& S n(n=18) t=\Delta /(4.35 \pm 0.09)+5.08 \\
& S^{*}(n=16) t-A /(3.66 \pm 0.09)-2.30 \\
& S g(n=20) t=A /(3.29 \pm 0.11)-2.92
\end{aligned}
$$

Con las estaciones sismologicas espanolas del borde mediterraneo de la peninsula se han determinado las siguientes ecuaciones de propagacion entre Argelia y la peninsula:

$$
\begin{aligned}
& t=A /(7.96 \pm 0.26)+4.95(n=24) \Delta>200 \\
& t=A /(5.71 \pm 0.28)-3.19(n=16) \Delta<200 \\
& t=\Delta /(4.33 \pm 0.15)+3.12(n=22) \Delta>200 \\
& t=A /(3.15 \pm 0.18)-8.50(n=14) \Delta<200
\end{aligned}
$$

Usando las anteriores velocidades de la corteza obtenida, hemos deducirlo un valor aproximado de espesor de la corteza para el area continental de la peninsula ( $\Pi$ aprox. $31 \mathrm{~km}$ ), asi como para el brazo del Mar Mediterraneo aquí considerado ( $H$ alrededor de $25 \mathrm{~km}$ ). Estos valores son solo aproximados y se trataran de comprobar en una segunda publicacion acerca de la dispersion de las ondas superficiales en el mismo area.

Se ha estudiado tambien la energia relativa entre las diferentes fases, encontrandose que la distancia es el factor principal en la correlacion. Aparece claro que, para cada terremoto dado, pasa mas energia a las ondas de cizalla que a su correspondiente onda longitudinal. Tambien la $P g$ parece atenuarse relativamente mis con la distancia que la correspondiente $P n$ y $S g$ para cada 
terremoto dado. La $P g \mathrm{y} s g$ se registran debiles o no se registran cuando el rayo sismico atraviesa la region mediterranea entre Argelia y Espana. Sin embargo los terremotos de la region de Alboran dan en Toledo claros registros de esas dos fases.

\section{INTRODUCTION.}

The most frequent mothods used in Seimology to study the crustal structure of the Eurth are: a) By means the determination of the velocities of the phases generated by near earthquakes; b) Studying the surface waves dispersion eurves from either far on near earthquakes as well as nuclear explosions; and $c$ ) Milking use of the reflected or refracted waves throughout the different crustal layers, artificial explosions being used better than earthquakes, that is by means the normal methorks of the seismic: prospection.

This paper concerns to the first method above mencioned, though there is in preparation a second paper related to the $b$ paragraph. The main purpose of both papers is the determination of the crustal-mantle structure for the Iberian Peninsula area and for the part of Mediterranean sea between the Peninsula and North Africa.

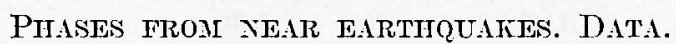

The near earthquakes records $(\Delta<1.000 \mathrm{~km}$ ) filed at the Toledo Observatory since 1950 up to now were reviserl. We began by selecting those whose seismograms at Toledo were very clear and among these we chose only those the $P$ phase of which was recorded clear enough at the rest of the Spanish Seismological Stations.

Making use of the arrival times of the crustal phases to the Observatories of the Spanish Net, it was made for ach one of the earthquakes so selected, a careful determination of the epicenter and origin time with the graphice method pointer ont by G. A. Eibv and M. G. MInir (1961). Also was found a value for the focus depth applying this method for diflerent depths and selecting the depth which fitted better with all data. This simple method when it is earry our with care, repeating several times the determinations and revising the values desviated of excluding them, if necessary, may lead to excellent results. specially when we deal with earthquakes of small magnitude, as in our case, recorderl only by the group of Observatories close to the epicenter. 


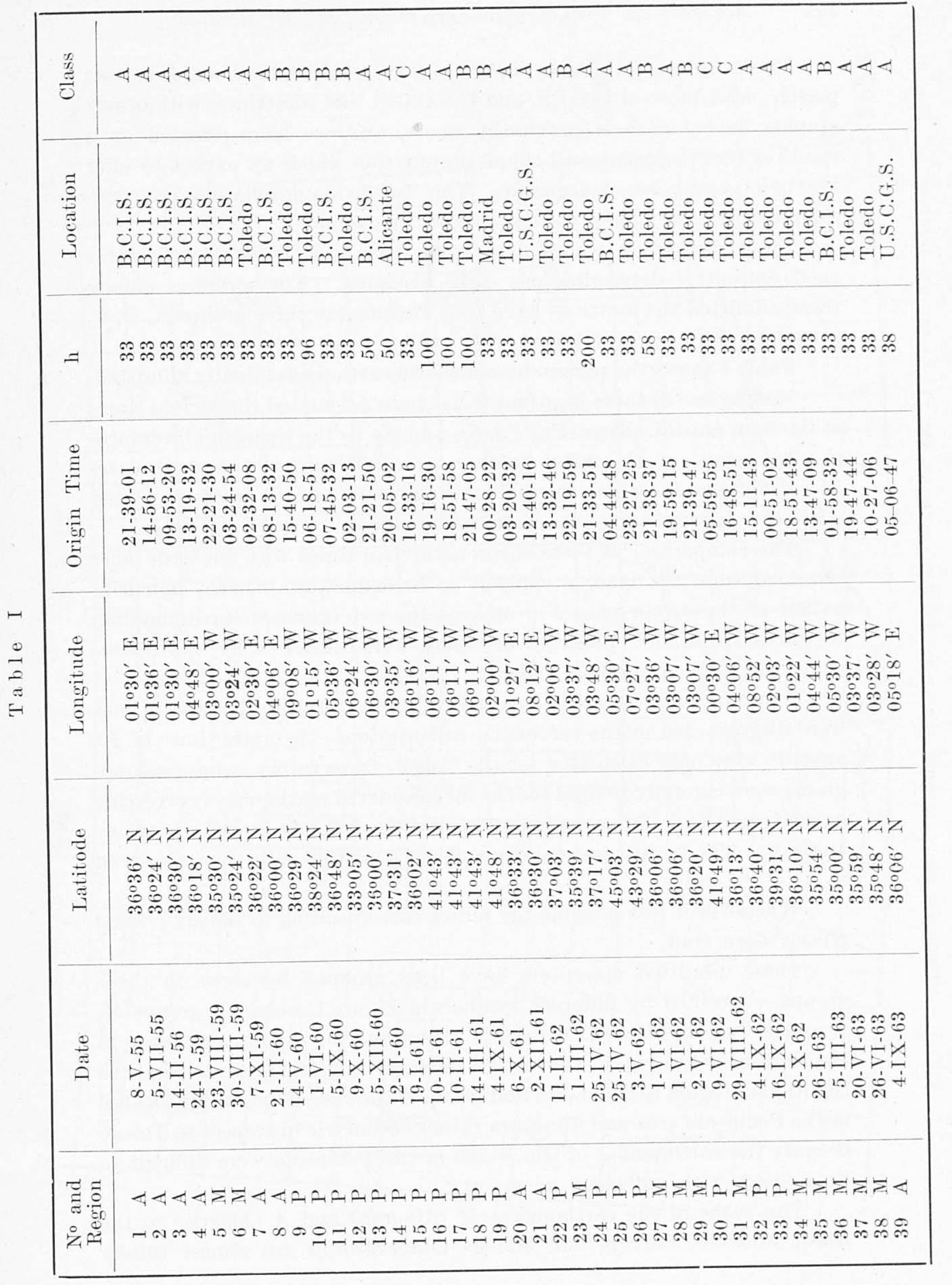


These epicentral determinations were compared, always it was posible, with those of B.C.I.S. and U.S.C.G.S. and sometimes with others graphic determinations previously made, and we have selected as a result of these comparisons, the detemination which we expect to offer the best guaranties of accuracy. The Toledo determination was considered when the others were practicaly the same.

The earthquakes whose data were scanty or in disagreement for good epicentral determinations were excluded. Furthermore, among those admitted the locations have been classified in three groups $\Lambda, B, C$, according the degree of accuracy.

Table I shows the parameters of the 39 authqualies finally andmitted.

Making use of these locations it has been calculated the arrival times of the four erustal phases $P n, P g$, Sn and $S g$ to the Spanish Observatories by means of the Eiby tables, exception made of several cases $(\Delta>900 \mathrm{~km})$ for which the arrival times of $P g$ and $S g$ were calculated with the Jeffreys tables for near earthquakes.

The comparison of these theoretic arrival times with the true ones obtained from the records enabled us to deduce the correct indentification of these four phases or at least the two impulses corresponding. to $P n$ and $S n$. The epicentral distances were calculated by coordinates using the Ritcher method (1960),

The impulses scattered remarkably from the theoretic arrival times were disgregarded in the suceessive calcultations. Theoretic times of $P$ * and $S^{*}$ were only calculated for the Toledo Observatory, whose seismograms were carefully revised for the 39 considered earthquakes correcting or ratifying the readings made on the records of Toledo in other previous analysis. The scanty onsets of possible $P^{*}$ phases only were observed if $\Delta>350 \mathrm{~km}$.

Whenever it was possible the pulses corresponding to the six crustal phases were rean.

These almitted epicenters have been grouped by zones in three groups, expecified by difterent symbols in Figure 1, named "groups $M$, $A$ and $P "$ in the Table $I$. Group $M$ represents the arthquakes close to Mediterranean sea region known as Alboran Sea; group $A$ corresponds to the Algeria region earthquales and group $P$ the rest of epicenters located in the Peninsula area and in a form rather assimetric in respect to Toledo because the earthquakes of the North of the Peninsula were difficult to be located with sufficient accuracy.

The paths of the earthquakes $M$ (Alboran) and $A$ (Algeria) to the Ebro, Alicante, Cartuja and Malaga Observatories are almost totally 


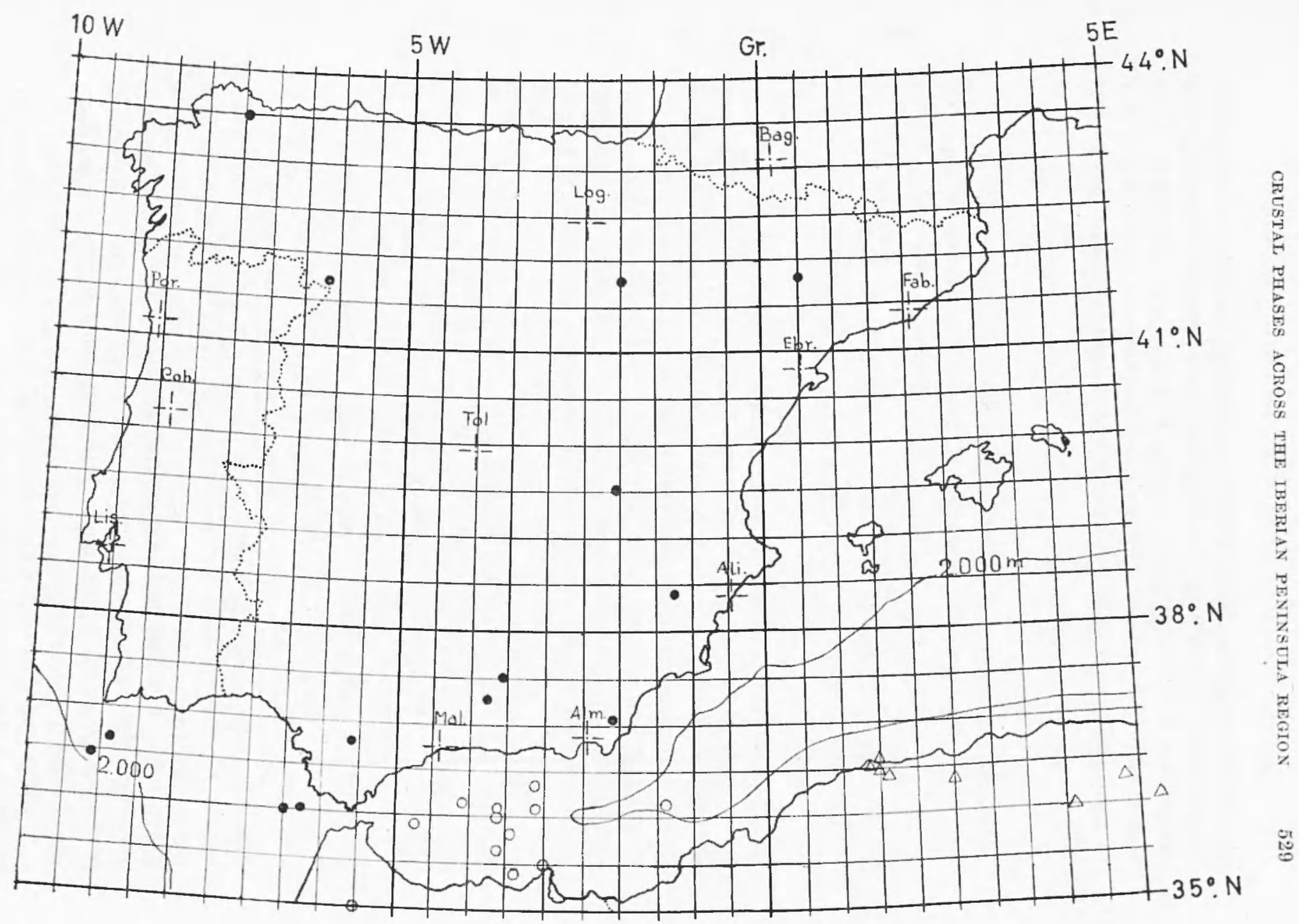

Fig. 1 - Epicenters and Stations. Note: Earthquakes number 12, 21, 25 are not plotted. 
covered by the water of the Mediterranean sea, therefore we have considered them to be similar and they have been grouped in the following alculation: With the arrival times of the first $P$ phase recorded at one or several of the Spanish stations above mentioned, corresponding only to these two groups considered, a travel-time eurve formed by two seg-

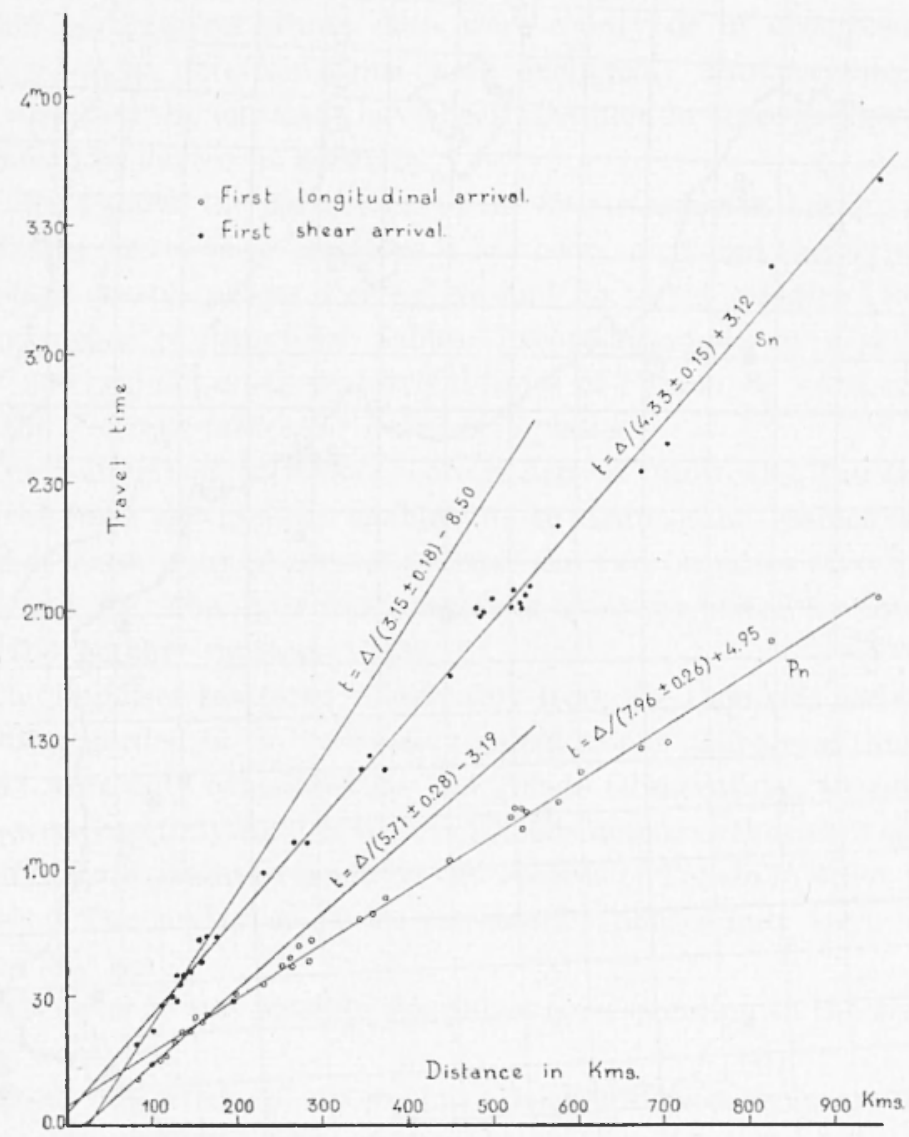

Fig. 2 - Travel time for the Mediterranean Sea.

ments las been determined (Figure 2). The refore, first of all the data have been plotted in a tarvel-time graphs where the discordant arivals have been excluded, which generally corresponded to confuse readings or to less acurate locations.

Afterwards the arrivals have been divided in two groups (Figure 2) according as the epicentral distance were larger or lesser than $200 \mathrm{~km}$ 
because we observed a change in the slope of the travel-time curve around this distance. The mean straight lines of these two groups have been obtained by the least squares method, obtaining:

$$
\begin{array}{ll}
t=\Delta /(7.96 \pm 0.26)+4.95 & (n=24) A>200 \\
t=\Delta /(5.71 \pm 0.28)-3.19 . & (n=16) A<200
\end{array}
$$

A similar clasification and calculation has been carried out for the first $S$ phase recorded at the same Observatories. The least squares method gives rise the next equations:

$$
\begin{array}{ll}
t=\Delta /(4.33 \pm 0.15)+3.12 & (n=22) \Delta>200 \\
t=\Delta /(3.15 \pm 0.18)-8.50 & (n=14) \Delta<200
\end{array}
$$

On the other hand the phases, corresponding, to the groups of earthquakes $M$ and $P$, have been recorded at Toledo Station through paths almost enterely continental. Once these phases have been revised directly on the seismograms of Toledo and rejected the values abnormally deviated as was made in case before, travel-time mean straight lines have been alculated, by use of the least squares, for the six normal crustal phases frequently considered in near earthquakes. The results were the equations:

$$
\begin{array}{lll}
P n & (n=25) & t=\Delta /(7.58 \pm 0.21)+1.92 \\
P^{*} & (n=15) & t=\Delta /) 7.24 \pm 0.26)+7.60 \\
P g & (n=19) & t=\Delta /(5.89 \pm 0.20)+1.94 \\
S n & (n=18) & t=\Delta /(4.35 \pm 0.09)+5.08 \\
S^{*} & (n=16) & t=\Delta /(3.66 \pm 0.09)-2.30 \\
S g & (n=20) & t=\Delta /(3.29 \pm 0.11)-2.92
\end{array}
$$

In the Figure 3 it can be seen these Travel-time lines, where the data used for their calculations have been drawn with small symbols. The phases of the Algerian (A) group of earthquakes have been plotted with larger symbols only to take a comparative idea in relation to the straight lines calculated, in order to observe if the mixed path Algeria-Toledo produces some alteration in the velocities observable on the travel time curves.

The standard deriations obtained, gives a clear idea of the dispersion of the points around the mean struight lines and they were calculated assuming the independent term of those equations to be fixed. 


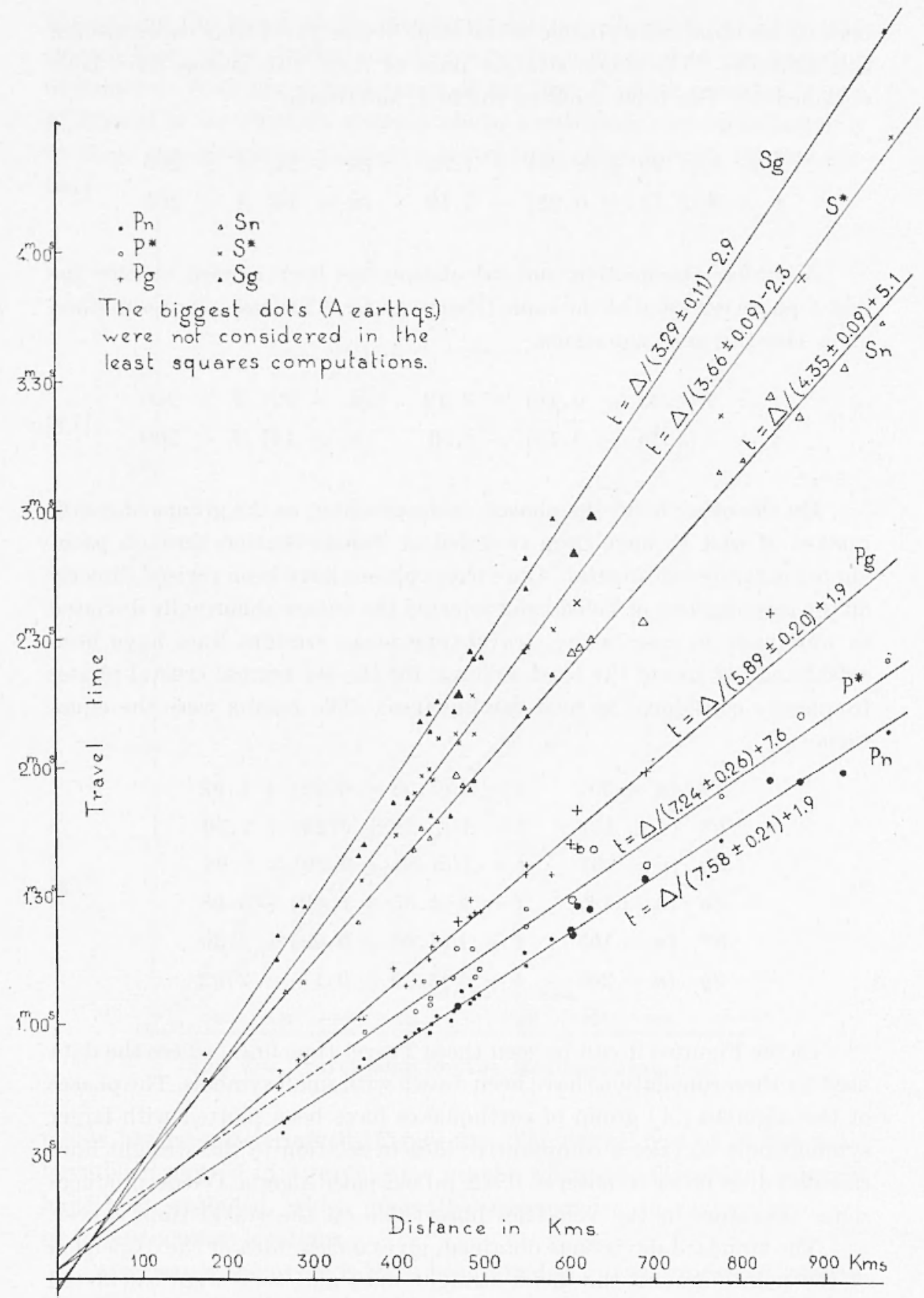

Fig. 3 - Travel time curves for Toledo 


\section{SOME OBSERVATIONS.}

The standard deviations of the obtained velocities in the equations [1a], [1b] and [2], are reasonable and fairly small if it is taken into account that we have ntilized different earthquakes, besides the great influence that the inevitable slight errors have over the epicentral location and the origin time, as well as because we have considered all the earthquakes with the same normal depth which, of course, is not really true. If we admit the velocity in the mantle to be constant in the upjer 100 kms (Nuttli O. WV. 1956) the velocity of $P n$ should not be too much affected for small variations in the focal depth (Table I), which is what actually happens.

It can be observed that the value of standard deviation is less for shear than for longitudinal waves. This fact can be attributed to the lesser amplitudes of the longitudinal waves in the near earthquakes which makes more imprecise their onsets or perhaps because the possible errors in the origin time affect more the longitudinal than the transversal waves becaluse of the difference between their velocities.

Nevertheless we have not found any signifieant reduction in the values of the standard deviations when we consider only the elear impulses noted with $i$, which means the dispersion of the data is mainly due to inaceuracies in the determination of the parameters of the earthquake or to the heterogeneity of them.

Systematie or particular observations have been:

a) The Algerian earthquakes (A) do not show any onset well defined corresponding to $P g$ and $S g$ phases. That has been the cause sometimes of misinterpretations in the routine works of the Observatory, interpreting as $S g$ the $S n$ wave. Phases $P^{*}$ and $S^{\text {* }}$ do not appear clear either. Possibly these facts are due to alterations in the first crustal layers for this narrow zone of the Mediterranean Sea.

In recent studies (B. K. Balavadze, P. SIL. Mindeli, 1963) reffered to the Black Sea, it is pointed out that the granitic layer disappears in the crust below the deep water of this sea. But these alterations of the granitic layer not only oceurs at inner seas but also happens at seas close to the continents as the Mediterranean region considered here.

b) In general the earthquakes with epicenters located at the border's in or the interior of the Peninsula, especially those of the Northern part, show a major number of clear impulses than the other earthquakes. 
$A$ good example is the $n^{\circ} 26$ (Asturias earthq.) in which $P n$ and $P g$ appear as double plases.

The earthquakes of the Alboran ( $M$ ) region give often $P g$ and $S g$ thatses which seems to indicate the existence of a granitic layer in the crust of this part of the Mediterranean. It is to be observed that the water deeper than $2.000 \mathrm{~m}$ (Figure 1) does not reach the Alboran region but they cover the arm of the sea between Algeria and Spain. It is noticeable that the earthquakes no 13 and 15 , even having clear seismograms, do not show other erustal phases than $P n$ and $S n$ in spite of the short path covered by the water. Certainly the thimness of the crustal granitic layer approaches near the coast for this Atlantic side, even though both epicenters are still in shallow water. Besides, the earthquake no 13 seems to be deeper than normal.

c) The depth assumed for almost all the considered earthquakes was the value named "normal», i.e. $H=33 \mathrm{~km}$, since the Eiby tables are based on that by Jeffeys-Bullen (1910). Although some earthquakes appear in the Table I with depths superior to the normal value only one earthquake (no 2.1) seems to fit better at the depth $H=200 \mathrm{~km}$, which also seems to be confirmed because the arrival times of $P n$ and $S n$ were not possible to be taken into account for being considerably deviated.

Also is to be noted that the $N^{\top}$ component of our Sprengnether seismograph recorded an impulsive surface wave with velocity $2,7 \mathrm{~km} / \mathrm{sec}$. and a period somewhat large $(T=6.0)$ which is not frecuently recorded in shallow near earthquakes.

\section{ThiCkNess OF 'THE Crusti. Discussiox.}

As is it well known the inverse of the slope of the travel time curves can be considered as the wave propagation velocity in the lowest point of the ray, for either longitudinal or trisversal movement. We can thus assign the velocities computed in the equations [1] and [2] to those velocities in the different layers of the crust and mantle in which the ray of crustal phases, here considered, have their lowest point.

The constant terms $\tau$ of the equations [1] and [?] are functions of the velocities and thickness assumed for the layers as well as of the focus depth $h$. If a two layered crust for example, is assumed overlying a half-infmite mantle it is possible to ealculate the thickness of the layers if we suppose to be known a relation $r$ between them, that is when the 
total crustal thickness is $H=H^{\prime}+r H^{\prime}$, where $H^{\prime}$ is the thickness of the thinner layer.

If $v_{1}, v_{2}$, and $v_{3}$ are the velocities in the three mentioned layers, $h$ the focal depth and known $\Delta_{3}=v_{3} \tau$, the thickness $H^{\prime}$ is a relation of the form:

$$
H^{\prime}=\frac{\Delta_{3}+h f_{2}\left(v_{2}, v_{3}\right)}{f_{1}\left(v_{1}, v_{2}, v_{3}, r\right)}
$$

where $f_{1}$ and $f_{2}$ are functions only dependent upon the velocities and $r$, which are known. Even if the functions $f_{1}$ and $f_{2}$ are simple relations easy to be calculated by means of the Snell's law, identic or similar value of $H$ is obtained simplifying the above formula adopting an average velocity

$$
v_{c}=\frac{v_{2}+r v_{1}}{1+r}
$$

for all the crust. Then we have

$$
H^{\prime}=\frac{\left(\frac{\Delta_{3}}{\operatorname{cotg} i}+h\right)}{2(1+r)}
$$

where sen $i-v_{c} / v_{3}$ and $A_{3}$ is taken negative.

In the relation of parameters compiled by Gutenberg (1959) for the crustal thickness of Europe, whose determinations were made by different investigators, the average value that we have obtained for $r$, is $r=2.02 \pm 1.09(n=13)$, disregarding the last two values considerably deviated.

And not only in Europe but in other regions, of continental structure of course, the thickness of the granitic layer is often taken as double of that for basaltic layer $(r=2)$ in the computations of the crustal thickness. If we use this relation also, perhaps not far from the reality, the above formula gives us

$$
H=\frac{\left(\frac{\Delta_{3}}{\operatorname{cotg} i}+h\right)}{2}
$$

where the total thickness $H=3 H^{\prime}$ appears.

This simple formula [3] has the inconvenience for us that we have to use a single value of $h$ for an heterogenous group of earthquakes. Therefore it only can be used to get a rough idea of the crustal thickness as a function of an average value of $h$ for all considered earthquakes. Assumed $h=33 \mathrm{~km}$, as Jeffreys use to take and using the parameters 
from equations [2], the [3] formula gives $H=28 \mathrm{~km}$, if we use $P$ waves and $H=31 \mathrm{~km}$, if we take $S$ wares. This last value obtained from the shear waves should be the most applopriate because the standard deviation for the $S$ wave equations are lesser than those for $P$ waves.

$A s$ it is comprehensible, the great influence of $h$ upon $H$ limits the availability of values found for the thickness of the crust, whose determination more precise we will try to find in the studies about dispersion of the surface waves, a paper about which has been undertaken. Nevertheless these values of the thickness are almissible and very similar to the mean value for Europe ( $H=31,0 \pm \check{\mathrm{s}} \mathrm{km}$ ), dedueed from different determinations (Gutenberg 1959).

It is to be observed that in order to get an availuble value of the crustal thickness ranging between 28 and $40 \mathrm{~km}$, by means of the [3] formula and using $S$ waves and considering $h$ as a linear function of $H$ (i.e. $h=h: H$ ), we have to give to the constant 7 : values langing between 1.0 and 1.30 , which seems to indicate that $h$ is larger than $H$. Then it might be thought that the major part of Iberian earthquakes have their hypocenters below the Mohorovicic discontinuity. It is also to be noted that the formula [3] deduced for $r H<h<(r+1) H$ still follows being valid, because the $i$ angle is searcely affected by smatl variations of $h$ on account of the smatiness of the depth increments in relation to the epicentral distances.

It is not easy with the data of the equations [1a] and [1b] to deduce the crustal thickness, even only approximated, for the part of the Mediterranean sea here considered. In fact even assuming the velocities given by equations [1a], $A<200 \mathrm{~km}$, to be the velocities for refracted waves through a first granitic layer and those $7,96 \mathrm{~km} / \mathrm{sec}$ and 4,33 $\mathrm{km} / \mathrm{sec}$ to be the velocities of $P$ and $S$ in the material just below the Moho, the existence of an intermediate layer and the thickness of it in relation to the first considered layer, would always remain doubtful.

Nevertheless in order to make an approximate estimation of $\Pi$, it might be assumed this half-continental mediterranean crust as formed by a two-layered structure, with the same thickness for both layers $(r=1)$, overlaying a half-infinite substratum where the shear velocities were for the three layers $v_{1}=3.15 \mathrm{~km} / \mathrm{sec}, v_{2}=3.53 \mathrm{~km} / \mathrm{sec}$ and $v_{3}=1.33$ $\mathrm{km} / \mathrm{sec}$. The $v_{1}$ and $v_{3}$ values taken from the equations [1b] and $v_{2}$ dedueed from $v_{1}\left(v_{2}=m v_{1}\right)$, where we have adopted for $m$ (ratio between the shear velocities in the basalt and in the glanite) a mean value ( $m=1.12$ ) obtained from the $S y$ and $S^{*}$ volocities collected by Gutenberg (1959) for several places of Europe. 


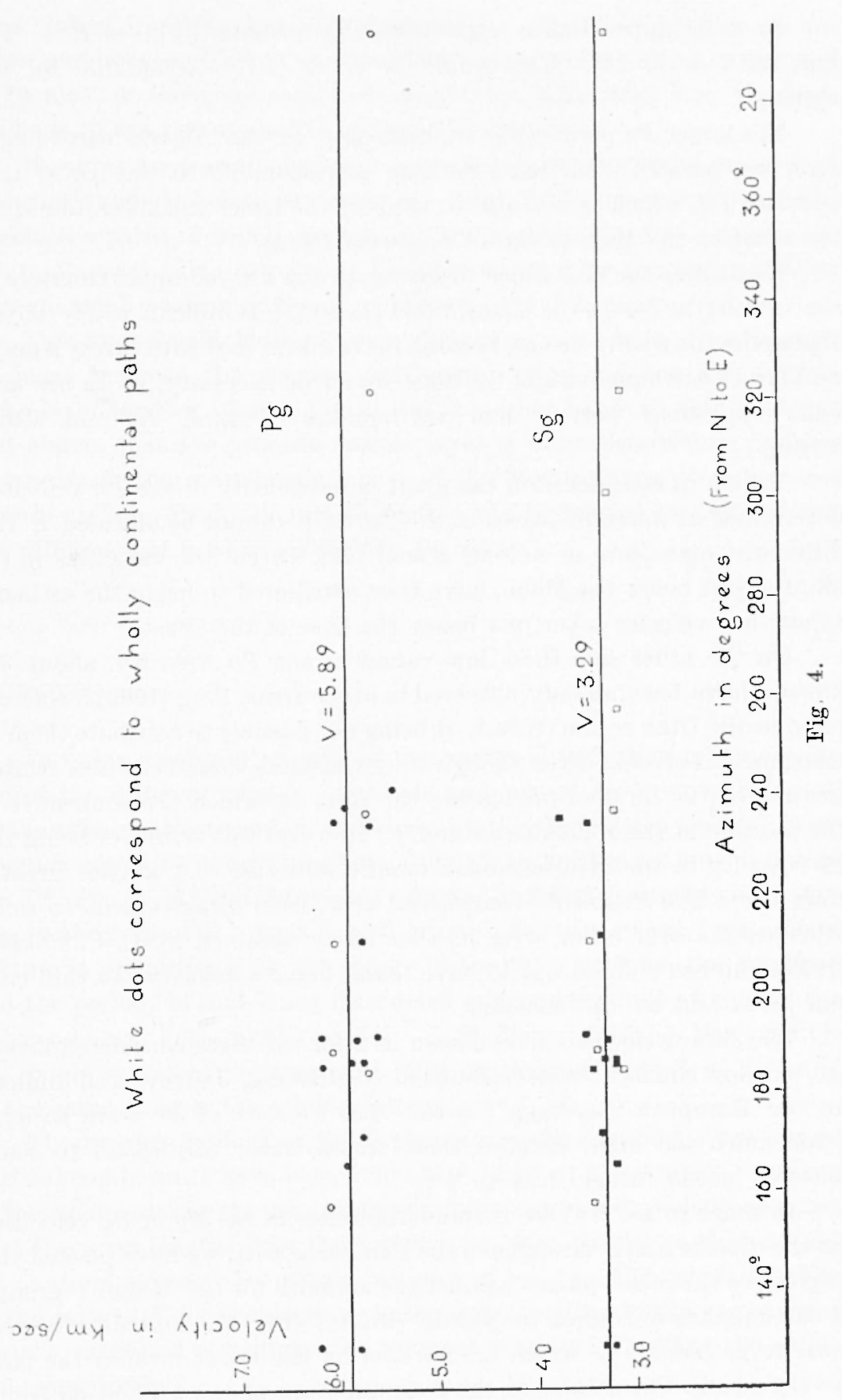


In these approximate hypotheses the formula [3] gives $H=2-1,6$ $\mathrm{km}$, for $h=33 \mathrm{~km}$. This value of $H$ is fairly acceptable for this regrion.

The larger $P n$ points (Fig. 3), belonging to the Algeria earthquakes (A), are parallel and above the line corresponding to the travel time curve of $P n$, which serves also to support the lesser thickness found for the crust of the Mediterranean Sea considered.

Regarding the difference observed of $0.4 \mathrm{~km} / \mathrm{sec}$ approximately in the velocity of $P n$ on the equations [1a] and [2], is difficult to say if this represents the reality or not, because for to affirm that with surety a major number of earthquakes and Stations would be necessary, or to use artificial explosions better than earthquakes (Berg J. W. and alters, 1.960).

Taking in consideration the great heterogeneity of the $P n$ velocities determined at different places of the Earth, it annot be affirmed if this difference represents or not an actual fact. Often low velocities in the Mantle, just below the Noho, have been attributed to begin the asthenosphere low velocity layer just below the base of the Crust.

On the other side these low values of the $P$ n velocity, about 7.6 $\mathrm{km} / \mathrm{sec}$, have been already observed in other areas. Berg (1960) has found them in the Utah region (U.S.A.) it being not possible to attribute them to instrumental errors. Even though Berg considers these velocities related to the Miantle, he does not decide the form on which are connected to the position of the BLoho discontinuity. However this result, of being the $P n$ velocity in the Mediterranean mantle structure, $0.4 \mathrm{~km} / \mathrm{sec}$ greater than below the Peninsula continental area, is in disagreement to some other results over other areas as that lately obtained by L. C. Pakiser (1963) who has pointed out to have found low $P n$ velocities in thin crustal areas and on the contrary.

The shear velocity values shown in 2 for the three considered layers are sensibly equals to those admitted (Gutenberg, Jeffreys and Bullen) for the European "average" crust. The velocity of $P$ * seem to us a value much too high; perhaps these travel times correspond to some reflected phase rather than to $P^{*}$.

In order to see if there is some difference in the $P g$ or $S g$ relocities for the diverse paths throughout the Peninsula area, we have plotted the velocity of these two phases against the azimuth for the $M$ and $P$ groups of earthquakes in respect to Toledo Station (Fig. 4). Full dots correspond to paths part of which are covered by the water (even if the part is very small). Correction for the constant term of the $P g$ and $S g$ equa- 
tions, taken from [2], has been introduced. $\Delta s$ it can be seen in the figure is not observable any clear tendency in the points which correspond to $P g$ most of them are scattered around the horizontal line that corresponds to the mean admitted value $5.89 \mathrm{~km} / \mathrm{sec}$.

However for those points eorresponding to $S g$ has to be mencioned that the symbols below the constant value 3.29 correspond to earthquakes the paths of which are enterely continental. On the contrary the points above the line correspond to paths covered by the water at least in some small portion of them, as those of the Alboran region.

This fact should indicate some difference perhaps in density or in thickness between the granitic continental layer and the first crustal rocks layer for the Alboran regrion. On the other hand we think, as was said above, that the granitic crustal layer is very distorted or perhaps dissapears in the most oriental part of the Nediterranean Sea between Algeria and the Peninsula. Both facts could be related to that pointed out difference of $0.4 \mathrm{~km} / \mathrm{sec}$ for the $P n$ waves.

\section{ENERGy.}

In order to obtain an idea of the energy distribution among every one of the different phases, anplitude and period mesurements for all earthquake phases recorded at Toledo Station have been made. If we assign consecutive integer numbers, from 1 to 6 , for the six crustal phases $P n, P^{*}, P g, S n, S^{*}$ and $S g$ we can express the relation among their energies in the form $\mathrm{Eji}$. As it is well known the wave energy per unit of volume is proportional to the square of the ratio between the amplitud and the period, so that being considered energies per unit of volume the relative energy ratio would be $E i j=\left(A-/ T^{2}\right) i:\left(A-/ T^{2}\right) j$. For example $E_{31}$ should represent the energy of $P g$ in respecting to that of $P n$, and in the same manner the other rolations.

The average periods of the 6 phases measured on the short period vertical components have been $0.99: 1.20: 1.08: 1.27: 1.20: 1.14$, taken in the same order as the crustal phases above cxpressed. It is to be noted that the wave lengths $\lambda$ for the 6 phases are very similar so that the $E j i$ ratios could express also energy per unit of length. The average values of the ratio $A / T$ for these same phases corresponding to the above mean periods, expressed in millimicrons per second, are $65: 87: 232: 196: 153$ : 340 respectively. 
As can be seen, except the two first values of $P n$ and $P^{*}$, probably more affected by measurement errors because of the smaller amplitudes of these two phases, the others are very similars, which seems to indicate the velocity spectrum to be constant $(A / T=$ const.). But as the periods are very similar for the six phases, if we measure them on the short period components, we have tried to see if the ratio $A / T$ are more or less the same if the measurements are made on the horizontal components of the mean period seismographs of Toledo. Then, the periods obtained for $S n, S^{*}$ and $S y$ were 2,72: 2.99: 3.07 and their corresponding values of $A / T$, in millimicronss, were $896: 919: 2350$. We can observe that $A / T$ seem to increase with period, which should mean that $A / T$ is not really constant. Therefore it will be convenient to take this into account when the formula for determining the magnitude of near earthquakes has to be used.

As the most of the readings are made on the short period equipments when we analyze near earthquakes would be convenient to use these short periods components to determine the magnitude based on the value of $A / T$. If it is possible for the sake of unifying the criteria the $S g$ phase, generally the clearest one, should be used for getting the magnitude at this Peninsula areal.

Coming again to the values obtained for the relative energies among the different phases, Fig. 5 shows the correlation between the epicentral distances and the computed valued of $E i j$ for each one of the earthquakes utilized.

The fact that $E$ ij represent relations between the phases of at same earthquake, reduces the effect of the magnitude over those relations, as well as the influence from the energy partition at the surface reflections, so that, if we disregard the effect of the focal mechanism over the recorded energy, only the epicentral distance remains as important parameter in the correlation. Also the variation of the eurstal structure throughout the different paths might affect to the Eij. But in our case this factor enters when we consider the distance as parameter because the three groups of earthquakes ( $M, A$ and $P$ ), as belonging to regions which give rise to paths of different structure, correspond to different epicentral distance intervals as it can be seen in Figure 5 .

In this figure the scale of ordinates is logaritmic so the regression lines represent exponential functions of type $E i j=k e^{n}$ where $k$ and $n$ are constants. In the graphs of Fig. 5, the earthquakes corresponding to the Alboran, Algeria and Peninsula regions have been signalled with different symbols and we have drawn approximately the average straight lines for each one fo the relations considered. 
CRUSTAL PHASES ACROSS THE IBERIAN PENINSULA REGION

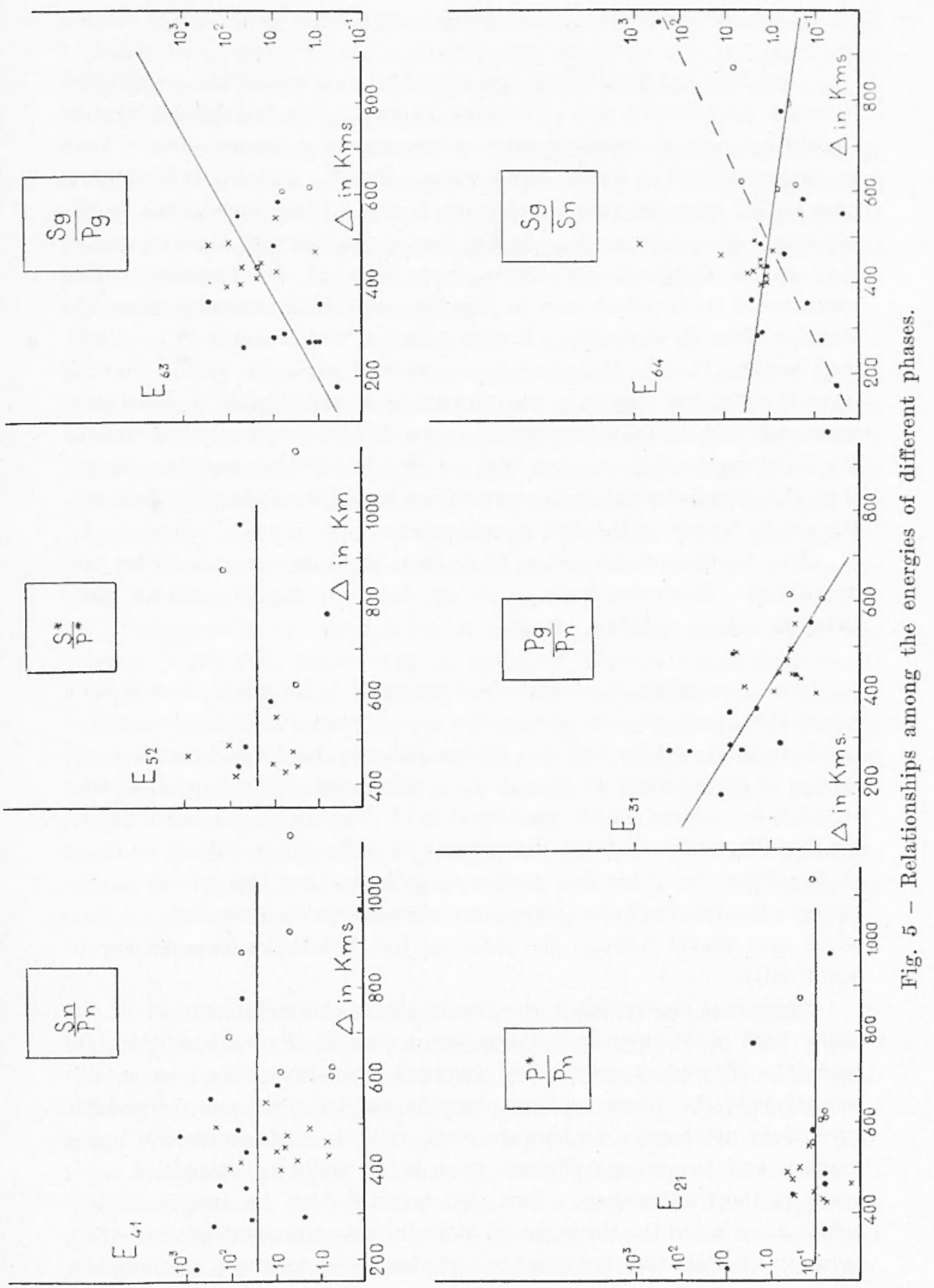


It can be observed:

a) For $E_{41}, E_{52}$ and $E_{13}$ is a clear fact that all points are situated between the values 5 and 100 for $E$. Therefore it is indubitable that in the three layers of the crust more energy passes to the shear wave than to its corresponding longitudinal wave. For $E_{41}$ and $E_{52}$ this value is near to 30 , as mean value, and there is not a clear dependence to the distance. However for $E_{03}(S g / P g)$ the earthquakes of $A$ lboran, region give values significatively larger than those of the Peninsula. This result could be an effect only of the distance, i.e. $P g$ suffering more absorption than $S g$ throughout the propagation which seems to be confirmed because the $\Pi_{g}$ phase has been observed generally weaker than $L g$ when the distance increases. Also the nuclei $M$ and $P$ could be considered separately and then this correlation assumed to be a regional effect or due the focal mechanism making the $P g$ of Alboram earthquakes weaker than the corresponding $S g$ in comparisson to the Peninsula earthquakes. We are in favour of the first hypothesis.

The Algerian earthquakes (only two) seem to contradict the first hypothesis. However, with so seanty data we do not consider these isolated values weighty.

b) The graph $E_{31}$ being observed there is no doubt that exists a correlation, that we can assume linear, between the distance and the ratio of energies of $P g$ and $P n$. This relation is also formed for the three groups of earthquakes $P, M$ and $A$, in this order, but nevertheless that correlation remains for the earthquakes of $P$ group considered independently. Therefore we think the correlation to be due mainly to an effect of the distance. This fact seems to indicate that the seismic waves through the granitic layer suffer more attenuation with the distance than when they travel through the material just below the Mohorovicic discontinuity.

This great absorption in the granitic layer chamnel in respect of the upper part of the mantle perhaps forms part of that observed fact of being the $\Pi g$ phases erroncously observed in relation to the frequent observations of $\mathrm{Pa}$ phases. The explanation might be because the granitic layer does not remain so homogeneous with the distance as the upper mantle, and the energy through that layer would be dissipated more easily in the transmission. This idea would further be supported considering separated the three groups of earthqu.rkes frequentely mentioned, because it is clear that the granitic layer has to be, for the $P$ earthquakes, 
more regular than for the $M$ earthquakes and the latter even more than that corresponding to the $A$ earthquakes as we have said before. The absorption of energy being consequently larger for these last earthquakes, as the points of the $E_{31}$ graph show.

In the above considerations we distegard the influence of the small difference observed in the average frequency of $P n$ and $P g$ because if this differenee were taken as significant the correlation found would strike a little with the conclusions pointed out by Khalturin V. I. (1963) who says that "the higher is the frequency, the stronger is the ampliturle decreased when distance increased".

c) Fol the case $E_{64}(S g / S n)$, homologous to the above case but with shear waves, the correlation is not so clear. If we exclude some particular cases we could take as average straight line that indicated in the figure with full line. This line is of lesser slope than that of the case $E_{31}$. Then the considerations of $b$ ) case could be valid here and this lesser slope might be justified because the $S g$ lost less energy than the $P g$, as we have seen. Clear examples of $L g$ and $s a$ have been often recorded on the seismograms.

The groups of earthquakes $M$ and $P$ do not show, considered isolately any clear slope. But the group of Alborin earthquakes seems to give a value for $E_{61}$ somewhat large than the group of the Peninsula. This $P$ group considered above perhaps could be regarded as forming the correlation indicated with the dotted line, different to the other; but this last correlation is not clear enough to be taken into aceount.

(l) The energy ratio $E_{21}$ ranges around the value 1.0 which indicates the little difference for that studied zone, between the absorption in the basaltic layer in relation to that in the region below the Morohovicic discontinuity.

e) The $A^{2} / T^{2}$ mean values for $P n$ relative to each group $P, I I$ and $A$ have been, excepting a constant factor, 13:57 and 475. Even if these values were affected by the magnitude, owing to that is very similar for all earthquakes considered, the difference in $P n$ energy between $A$ and $P$ earthquakes, seems to us to be significant. Herrin P. E. and Taggar J. (1962) find weak $P n$ phases in areas giving low velocities for $P n$ and the contrary. They attribute that to an attenuation effect. Regarding these ideas, these differences in the $P n$ encrgy seem to be in accordance to the lesser velocity that we have obtained for this phase in the Penin- 
sula area (7.6 $\mathrm{km} / \mathrm{sec})$ in respect the velocity $7.9 \mathrm{~km} / \mathrm{sec}$ fouml for the part of the Merditerranean Sear considered in this work.

Acknowledgments. - This research has been sponsored by Air Force of Scicntific Reserrch, OAR, through the European Offree of Aerospace Research, as part of the Advanced Research Project Agency's Project Vela-triform, aceorting the Contract $A F$ 61(052)-657. We wish to express our thanks for the assistance received from this Office.

\section{BIIBIIOGRAPIIY}

Badavadze B. K., Minjeli P. Sir., The Earth's erast structure of the Blach Sea basin from geophysical data. (Abstract) XIII. IUGG Assembly, 1963.

JBERG. .1. W. JR. and alters, Seismic Investigalion of crustal structure in the Easlern part of the Basin and Range Province, "BSSA " 50, 4 (1960).

Eiby G. A. and MUIr M. G., Tables to facilitate the study of near earthquakes. 1961.

Ewixg, W. M., Sediments of ocean basins. Publ. Jamont. Obs. 1963.

Ewing J. and Ewrsg M., Seismic-retraction measuremenls in the Atlantic ocean Basins, in the Mediterranean Sea, on the Mid-Atlantic Ridge, and in the Norwegian sea. BGSA, 70 (1959).

Gutensens: B., Physies of the Earth's Interior. (Book), 1959.

IImrin E. and Taggant J., Regional variations in Pn velocity and their effect on the location of epicenters. "BSSA " 52, 5 (1962).

IIOUTz R. F. and Ewixg J. I., Detailed sedimentary velocities from seismic refraction profiles in the Western North Allantic. "J.G.R.», 85, 18 (1963).

JeFresss II., Table for the near earthqualie pulses.

Kinlidurix V. I., The longitudinal and transversal waves absorption in the Earth crust. (Abstract), XIII. IUGG. General Assembly 1963.

Linemanx I., The limes of $\mathrm{P}$ and $\mathrm{S}$ in Northeastern America. "Ammali di Geofisica ", VIII, 4 (1955).

Nuttu. O. W., Tentative velocities of seismic crustal waves in the Central United States "Earlhq. Notes 27: 41-44.

PaKiser I. C., Structure of the Crust and Upper Mantle in the Western Uniled Stales. (Abstract), XIII. IUGG. Assembly, 1963.

Pentimfa E. and Sasstamornex P., On. the depths of earthquales in the Ballic shield. Univ. of Ilelsinki, 1963.

Romer C. and alters, Travel times and amplitudes of principal body phases recorded from (iNOARE. BSSA, 52, 5, (1962). 
Ryat, A., The Ilebgen Latie, Montana, earthquake of August 18, 19:59: P waves. BSiA, 52, 2 (1962).

Sanstamoryes P., Travel times for a crustal modes in Finland. "Geophysica", $7,4,(1963)$.

S'TAUDER W.S. J. and Boldinger G., Pn velocity and olher seismic studies from the dala of recent Southeast Missouri - Earthquakes. BSSA, 53, 3 (1963).

Tiryggvasox E. and Bitir M., Upper Crustal Structure of Iceland. "J.G.R. ", 66, $6(1961)$.

Trugrvason E. and BRTII M., Deep seismic reflection experiments at Kiruna. "Geof. Pura e Applicata ". 51 (1962).

Tvaltvanze, G. K., Sludy of Earth's crust structure on the basis of the evidence from near earlhquales. Travaux. Se. Fas., 22, 1961. 